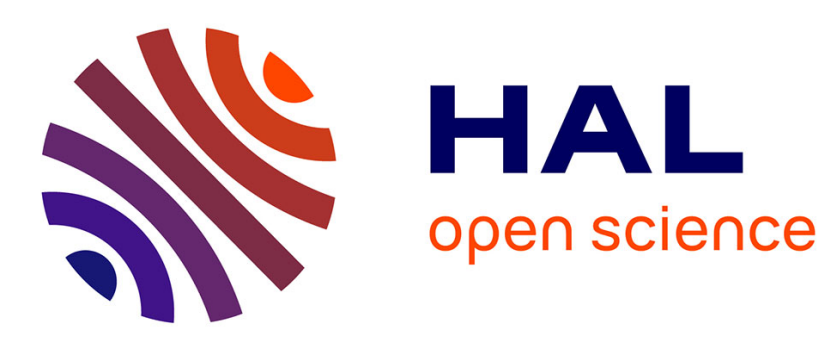

\title{
Orientation of carp, Cyprinus carpio L., to free amino acids from Tubifex extract in an olfactometer
}

Philippe Saglio, Benoit Fauconneau, J.M. Blanc

\section{To cite this version:}

Philippe Saglio, Benoit Fauconneau, J.M. Blanc. Orientation of carp, Cyprinus carpio L., to free amino acids from Tubifex extract in an olfactometer. Journal of Fish Biology, 1990, 37, pp.887-898. 10.1111/j.1095-8649.1990.tb03592.x . hal-02716213

\section{HAL Id: hal-02716213 \\ https://hal.inrae.fr/hal-02716213}

Submitted on 1 Jun 2020

HAL is a multi-disciplinary open access archive for the deposit and dissemination of scientific research documents, whether they are published or not. The documents may come from teaching and research institutions in France or abroad, or from public or private research centers.
L'archive ouverte pluridisciplinaire HAL, est destinée au dépôt et à la diffusion de documents scientifiques de niveau recherche, publiés ou non, émanant des établissements d'enseignement et de recherche français ou étrangers, des laboratoires publics ou privés. 


\title{
Orientation of carp, Cyprinus carpio L., to free amino acids from Tubifex extract in an olfactometer
}

\author{
Ph. Saglio*, B. Fauconneau $\dagger$ and J. M. Blanc $\ddagger$ \\ *Station d'Hydrobiologie, Unité d'Ecologie des Poissons, INRA, BP 3, F64310 \\ Saint-Pée-sur-Nivelle, †Station de Physiologie et Ecologie des Poissons, Université de \\ Rennes I, INRA, Campus de Beaulieu, F35042 Rennes, $\ddagger$ Station d'Hydrobiologie, Unité de \\ Nutrition des Poissons, INRA, BP 3, F64310 Saint-Pée-sur-Nivelle, France
}

(Received 1 November 1989, Accepted 2 July 1990)

\begin{abstract}
We analysed the effects of L-amino acid combinations, tested at the same relative concentrations as in $500 \mathrm{mg} \mathrm{l}$ ' of a filtrated Tubifex extract, on attraction and exploratory behaviour of juvenile carp, Cyprinus carpio L., in an olfactometer. Tubifex filtrate was significantly active in the range of concentrations tested $\left(5 \mathrm{mgl}^{-1}, 50 \mathrm{mg} \mathrm{l}^{-1}, 500 \mathrm{mg} \mathrm{l}^{-1}, 5 \mathrm{gl}^{-1}\right)$. Maximum attraction was obtained in response to a concentration of $500 \mathrm{mg} \mathrm{l}^{-1}$. Soluble TCA fraction and a mixture of the 17 synthetic amino acids found in this fraction also showed significant effects on attraction and exploratory behaviour. Tests of the four chemical groups of amino acids gave the following results: acidic amino acids (aspartic and glutamic) did not produce significant activity. Basic amino acids (histidine, arginine and lysine) and polar, uncharged amino acids (glycine, serine, threonine, tyrosine, asparagine and glutamine) were ineffective as attractants but significantly increased exploration. Non-polar amino acids (alanine, valine, leucine, isoleucine, phenylalanine, and methionine) showed significant effects on both attraction and exploration. In tests where different pairs of these amino acid groups were mixed it was shown that a combination of nonpolar amino acids and polar uncharged amino acids was the most effective in inducing both attraction and exploration. The simplest combination to have a significant effect on both attraction and exploration was alanine, valine and glycine.

These results are discussed in the light of recent data on the role of free amino acids in the behaviour of fishes.
\end{abstract}

Key words: Cyprinus carpio; chemical sense; olfactometer; attraction; L-amino acids; Tubifex.

\section{INTRODUCTION}

It has been shown that in water amino acids are released by a wide variety of organisms, ranging from phytoplankton (Fogg, 1966; Daumas, 1976; Hellebust, 1974), zooplankton (Nicol, 1967; Johannes and Webb, 1970) to vertebrates (Ogata et al., 1983; Olsén, 1986). Given the highly stimulatory effect of amino acids on the chemical senses of fishes (Caprio, 1982; Hara, 1982; Hidaka, 1982), dissolved free amino acids may be of great importance in the allelochemical and pheromonal communications of these vertebrates.

The role of amino acids as chemical signals evoking chemotaxis or feeding behaviour in aquatic animals has been reported in a number of phyla, from bacteria to fish (Lindstedt, 1971). In various freshwater and marine fish species, it has been shown that amino acid fractions isolated from food extracts can act as ' attractants', operating at distance (Hashimoto et al., 1968; Pawson, 1977; Atema et al., 1980; Harada \& Ikeda, 1984; Harada \& Matsuda, 1984; Olsén et al., 1986) or as 'stimulants', promoting ingestion (Carr \& Chaney, 1976; Carr et al., 1977; Adron \& Mackie, 1978; Tsushima \& Ina, 1978; Ina \& Matsui, 1980; Mackie \& Mitchell, 1983; Takeda et al., 1984; Johnsen \& Adams, 1986). 
In the carp, Cyprinus carpio L., amino acids constitute potent olfactory and gustatory stimuli (Goh \& Tamura, 1978; Kawamura \& Tamura, 1980; Marui \& Funakoshi, 1980; Marui et al., 1983). Our own earlier observations have shown that low concentrations of individual amino acids have an effect on the orientation of juveniles in an olfactometer (Saglio \& Blanc, 1983). The involvement of amino acids in the feeding behaviour of this species had been previously shown by Tsushima \& Ina (1978). These authors found that a mixture of the 17 free amino acids isolated from an extract of pupa of silkworm could stimulate feeding behaviour in the carp. However, data are lacking on the relative contribution of various combinations of free amino acids from a natural prey organism to the behavioural response of this species.

In the present study, we analysed the effects of free amino acids identified in an extract of Tubifex on the orienting and exploratory behaviour of immature carp in an olfactometer. Various combinations of synthetic amino acids, in the same proportions as in Tubifex extract, were tested to determine optimal mixtures eliciting attraction.

\section{MATERIALS AND METHODS}

\section{FISH}

Rearing of carp and behavioural observations were performed at the INRA experimental fish farm at Donzacq, Landes, France. Olfactometric tests were run in autumn 1986 with 500 carp (mean weight $17 \mathrm{~g}$ ), all from the same batch, grown in an outdoor pond of $200 \mathrm{~m}^{2}$.

Three weeks before observation, the fish were introduced to the olfactometric room and

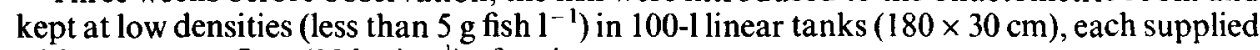
with a constant flow $\left(101 \mathrm{~min}^{-1}\right)$ of spring water.

The water temperature was $17 \cdot 5-18^{\circ} \mathrm{C}$ and the $\mathrm{pH} 7 \cdot 3-7 \cdot 4$. The total ammonia-nitrogen concentrations were $7-8 \mu \mathrm{g} \mathrm{I}^{-1}$ (Technicon). Fluorescent lights over the tanks were kept on between $07.00-22.00$ hours. Carp were fed daily at 12.00 hours on a mixture of frozen chironomids, tubificids and Cladocera (in equal amounts) corresponding to $5 \%$ of fresh body weight. The food organisms were obtained from a private supplier (Grebil Society). All tanks were cleaned regularly by siphoning.

\section{TEST APPARATUS (Fig. 1)}

The tests were run in parallel in two identical two-choice olfactometers. Each device was made of a 501 linear tank $(150 \times 25 \mathrm{~cm})$ with two inlets at either end (flow rate: $21 \mathrm{~min}^{-1}$ ) with a central evacuation.

Two $10 \times 10 \mathrm{~cm}$ shelters were positioned at the ends of each tank and one shadow screen $(20 \times 25 \mathrm{~cm})$ was set above the central outlet. The dripping test solution could be added (perfusor Souplix, R 30, Bruneau Laboratory) to the water flow alternatively at either end of each tank. The stimulated shelter is referred to as shelter $\mathrm{A}$ and the non-stimulated shelter as shelter $B$.

The olfactometers were isolated in a chamber covered with black plastic sheeting.

A fluorescent light and a camera, positioned above the olfactometers, were switched on before the introduction of fish. During the test, fish behaviour was observed from a $3-\mathrm{m}$ distance on a monitor screen (Sony videorecorder system).

\section{EXPERIMENTAL PROCEDURE}

All tests were run between 09.00 and 12.00 hours on groups of five carp. Each fish was tested only once.

Carp were introduced into the olfactometers $60 \mathrm{~min}$ before the test began. In most cases this acclimation period was necessary for the fish to settle into a stable swimming pattern, 


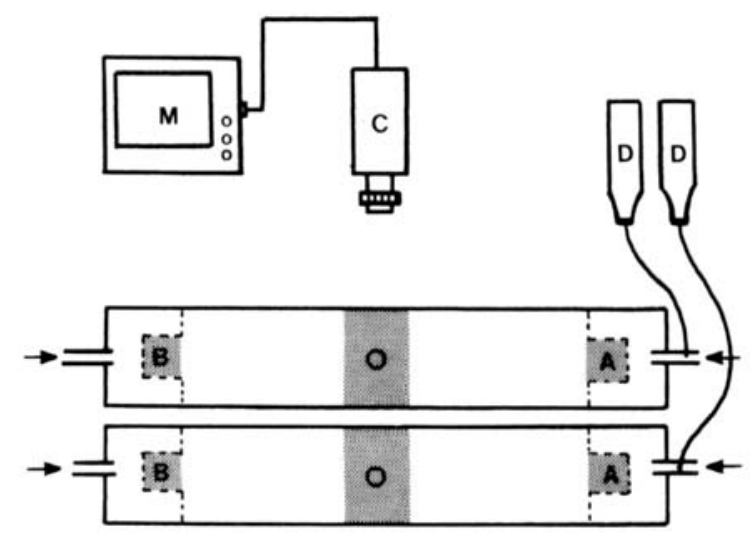

FIG. I. Experimental device. A, Stimulated shelter; B, non-stimulated shelter; C, camera; D, dripping solutions; $M$, monitor screen; $\rightarrow$, water inlets; $O$, water outlet.

with similar frequencies of visits to shelters $\mathrm{A}$ and $\mathrm{B}$, after a few minutes stay under the central shadow screen.

The behaviour of the test fish was then analysed on the basis of the number of visits to shelters $\mathrm{A}$ and $\mathrm{B}$ during two consecutive test periods lasting 10 min each.

During the first period, spring water was tested without test solution.

During the second period, $1 \mathrm{l}$ of test solution, made up with spring water, was continuously $\left(0.11 \mathrm{~min}^{-1}\right)$ introduced into the water flow above shelter A. Every test solution was tested twice.

This test apparatus was used to assess the effect of chemical stimuli on: (a) attraction choice of stimulated shelter; (b) repulsion-choice of non-stimulated shelter; (c) exploration-number of visits to both shelters.

\section{SAMPLE PREPARATION}

Crude extracts were prepared by macerating samples of $10 \mathrm{~g}$ frozen Tubifex for $5 \mathrm{~min}$ in 11 distilled water. The extracts were then filtered $(0.7 \mu \mathrm{m}$, Whatman GFF) and concentrated under vacuum. Free amino acids in the filtrates were extracted by homogenization in trichloracetic acid (TCA) solution $(10 \% \mathrm{w} / \mathrm{v})$ and by centrifugation $(4000 \mathrm{~g}, 30 \mathrm{~min})$. The TCA was removed from the supernatant by three successive extractions (mixing and decanting) with diethyl ether. The remaining diethyl ether was removed by evaporation under vacuum and the free amino acids recovered in double-distilled water.

\section{AMINO ACID ANALYSIS}

The L-amino acid concentrations were measured after orthophtaldieldehyde (OPA) derivatization with mercaptoethanol as a reducing agent to produce iso-indol derivates. The amino acid derivates were separated by HPLC (Vista 5000, Varian, France) on a C 18 micropack column (Varian, France) using a water-methanol eluting gradient (Hogan et al., 1982). The derivates were detected by fluorimetry. $\gamma$-Amino butyric acid (GABA) was used as an internal standard. Secondary amines, proline and hydroxy proline, were not analysed.

\section{TEST STIMULI}

In order to assess the stimulatory effect of different doses of crude Tubifex extracts on the behaviour of carp in the olfactometer, test solutions obtained after 5 min maceration and filtration of frozen Tubifex at $100 \mathrm{mg} \mathrm{l}^{-1}, 1 \mathrm{gl}^{-1}, 10 \mathrm{gl}^{-1}$ and $100 \mathrm{~g}^{-1}$ were prepared. Considering the flow rate of water at each end of the olfactometer $\left(21 \mathrm{~min}^{-1}\right)$ and the flow rate of the dripping test solution $\left(0 \cdot 11 \mathrm{~min}^{-1}\right)$, these solutions led to real test concentrations above the stimulated shelter of $5 \mathrm{mg} \mathrm{l}^{-1}, 50 \mathrm{mg} \mathrm{l}^{-1}, 500 \mathrm{mg}^{-1}$ and $5 \mathrm{~g}^{-1}$ respectively. 
TABLE I. Concentration of free amino acids in the filtrate of Tubifex $\left(500 \mathrm{mg}^{-1}\right)$

\begin{tabular}{lc}
\hline Amino acids & Concentrations $\left(\mu \mathrm{g}^{-1}\right)$ \\
\hline Acidic amino acids: & \\
Aspartic acid & $3 \cdot 8$ \\
Glutamic acid & $6 \cdot 8$ \\
Basic amino acids: & \\
Lysine & $12 \cdot 0$ \\
Arginine & $8 \cdot 1$ \\
Histidine & $9 \cdot 1$ \\
Non-polar amino acids: & \\
Alanine & $11 \cdot 7$ \\
Valine & $4 \cdot 3$ \\
Leucine & $7 \cdot 7$ \\
Isoleucine & $3 \cdot 3$ \\
Phenylalanine & $4 \cdot 3$ \\
Methionine & $4 \cdot 2$ \\
Polar, uncharged amino acids: \\
Glycine \\
Serine & $3 \cdot 7$ \\
Threonine & $6 \cdot 3$ \\
Tyrosine & $4 \cdot 2$ \\
Asparagine & $4 \cdot 2$ \\
Glutamine & $1 \cdot 7$ \\
Total & $0 \cdot 6$ \\
& \\
\hline
\end{tabular}

The stimulatory effect of soluble TCA fraction, reconstituted free amino acid fraction and combinations of individual amino acids were all tested at the same relative concentrations as in the $500 \mathrm{mg} \mathrm{l}^{-1}$ of crude Tubifex filtrate. Corresponding free amino acid concentrations are given in Table 1 .

According to this table, 43 different amino acid combinations were tested to determine their relative effects on attraction, repulsion and exploration.

The following testing schedule was applied for a selection of combinations:

In the first series of bioassays, the activity of each one of the four chemical groups of amino acids (based on R polarity) was tested. Associations between different pairs of these groups were then tested. Since strong activity was induced by mixing non-polar amino acids and polar, uncharged amino acids, we tested various combinations of amino acids from these two groups. These latter tests led us to select three amino acids which showed significant activity when mixed in the same proportions as in the Tubifex extract. This formulation was further tested in association with some amino acids from other groups (acidic and basic amino acids).

Sigma products (Kit LAA 21) were used from the reconstitution of the free amino acid fraction and for mixtures of amino acids. Crude extracts and amino acid mixtures were freshly made on the day of testing.

\section{DATA ANALYSIS}

The number of visits to shelters $A$ and $B$ before and during stimulation were analysed for the two trials of every test solution, using the G-test of independence (Sokal \& Rohlf, 1969).

The same method (independence and goodness of fit) was used to check for homogeneity among all the trials and for the balance of $\mathrm{A}$ and $\mathrm{B}$ visits before any stimulation. 
The reason for using the G-test instead of the classical $\chi^{2}$ computational procedure lies in the fact that the $\mathrm{G}$ statistic not only fits the theoretical $\chi^{2}$ distribution slightly better in the case of small sample sizes, but is also much simpler to use for the analysis of contingency tables (Sokal \& Rohlf, 1969).

\section{RESULTS}

\section{HOMOGENEITY AND GOODNESS OF FIT AMONG TRIALS}

The comparison of the before-stimulation records in the 98 trials (49 assays, two trials each) showed that there was no significant variation in the A : B ratio $(G=57 \cdot 1$, NS). The average proportion of A visits $(51 \cdot 2 \%)$ did not differ significantly from $50 \%$. Thus, the before-stimulation records should be considered as valid controls.

The comparison of responses to stimulation among trials within assays (49 replicated tests) did not reveal any lack of concordance between these trials (total $G=150 \cdot 1,147$ d.f., NS).

\section{OLFACTOMETRIC ACTIVITIES OF TEST SOLUTIONS}

The effects of crude extracts and free amino acid solutions from Tubifex on swimming orientation and exploratory behaviour are given in Table II.

Crude Tubifex extracts obtained through maceration and filtration for $5 \mathrm{~min}$ were highly stimulatory in the range of concentrations tested $\left(5 \mathrm{mg} \mathrm{l}^{-1}\right.$ to $\left.5 \mathrm{~g} \mathrm{l}^{-1}\right)$. Maximum attraction was observed in response to $500 \mathrm{mg} \mathrm{l}^{-1}$. At doses corresponding to $500 \mathrm{mg} \mathrm{l}^{-1}$ of crude extract, soluble TCA fraction and the mixture of the 17 free amino acids showed similar significant effects on both attraction and exploratory behaviour. These effects were close to those produced by crude extracts.

At the same dose, the four chemical groups of amino acids revealed significant differences in their relative stimulatory efficiency.

Acidic amino acids induced no significant behavioural effects. Basic amino acids and polar, uncharged amino acids were ineffective attractants but increased exploratory activity. The entire group of non-polar amino acids showed significant effects on both attraction and exploration. Within the six non-polar amino acids however, none of the four compounds combinations tested was attractive. Alanine, valine, phenylalanine and methionine significantly increased exploratory behaviour and alanine, valine, leucine and isoleucine were significantly repellent. Within the polar, uncharged amino acid group, glycine, tyrosine, asparagine and glutamine produced significant effects on both attraction and exploration. This latter formulation was more attractive than the combination of the six polar, uncharged amino acids. The tests showed that a combination of non-polar amino acids and polar, uncharged amino acids had the most effect on both attraction and exploration. The mixture of acidic amino acids and polar, uncharged amino acids was slightly repellent. The four other combinations tested increased the total number of visits to both shelters but did not influence choice of shelter.

Among the 11 formulations tested of non-polar and polar, uncharged amino acids, alanine, valine and glycine was the smallest combination of amino acids to show a significant effect on both attraction and exploration. Most of the formulations including these three amino acids were highly stimulatory. Among those, 


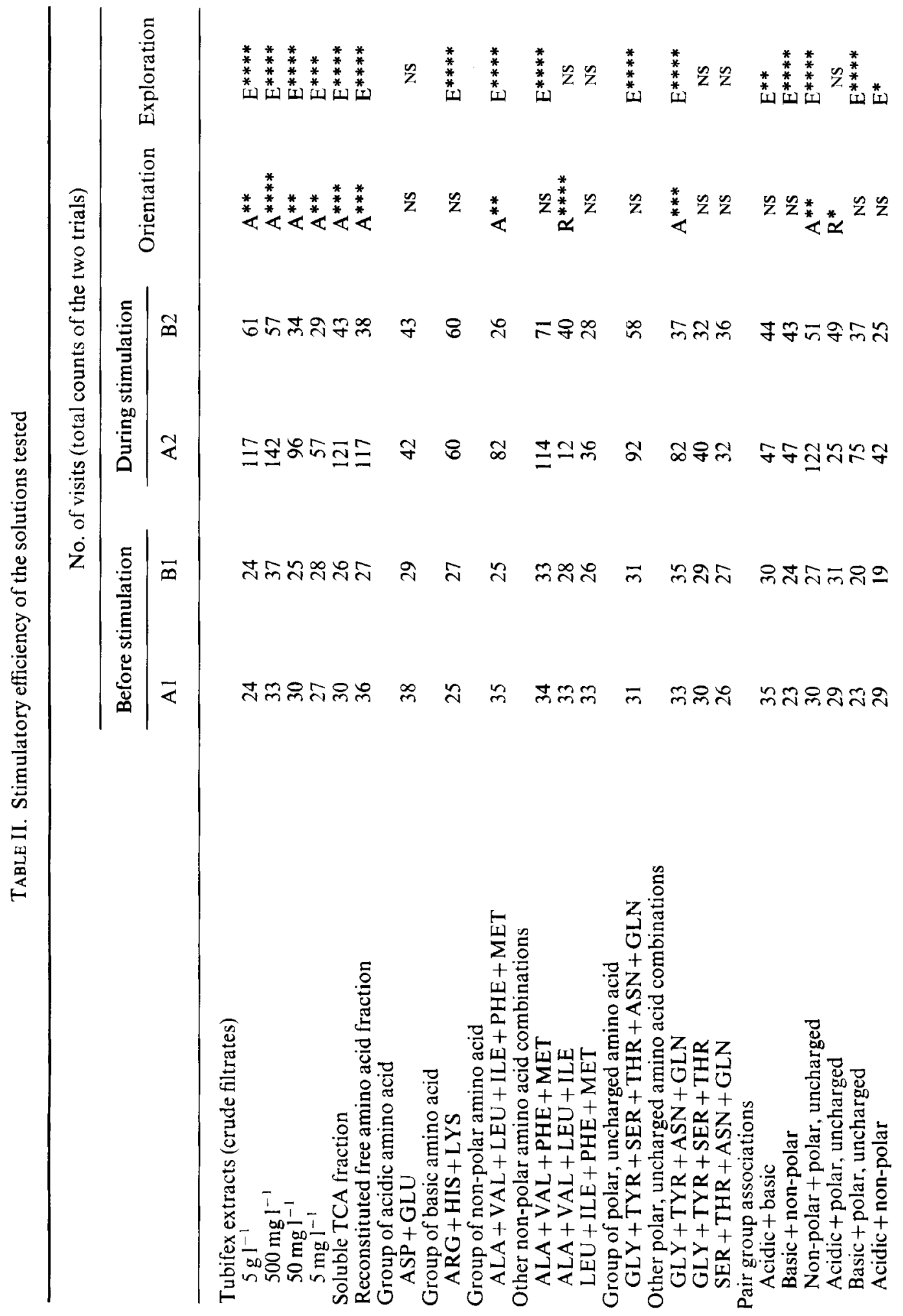




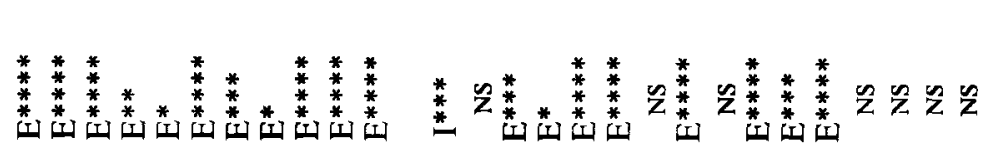

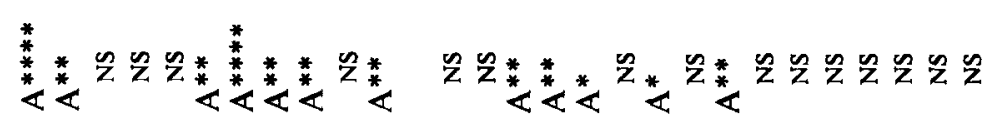

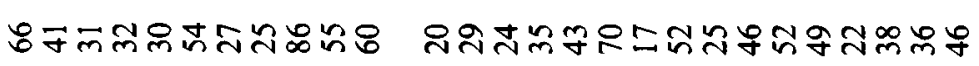

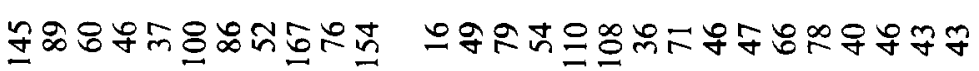

代

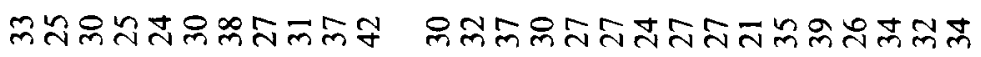

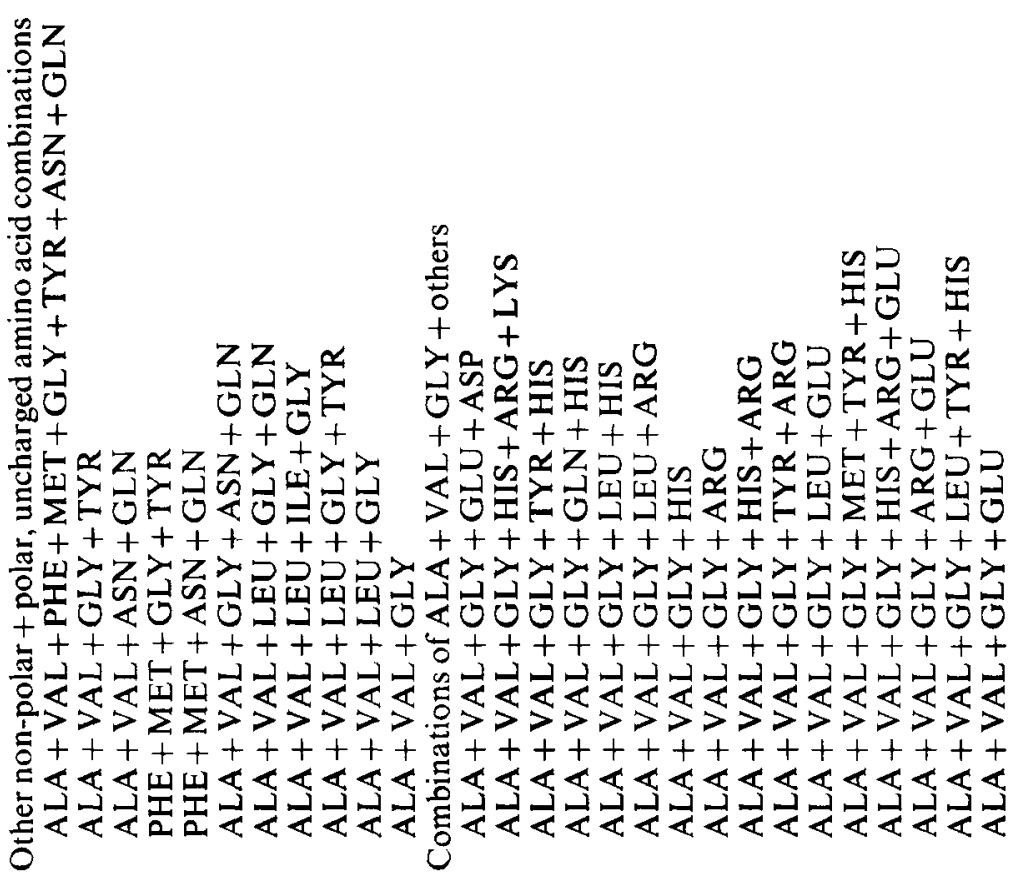


alanine, valine, phenylalanine, methionine, glycine, tyrosine, asparagine and glutamine, and alanine, valine, leucine, glycine and glutamine were the most active. The attraction induced by those two latter formulations was similar to the attraction induced by crude extracts.

The combinations of alanine, valine and glycine with amino acids from other groups produced smaller effects on average in both orientation and exploratory behaviour. The combination of the two acidic amino acids was not attractive and decreased the number of visits to shelters A and B. The combination of the three basic amino acids had no effect on either attraction or exploration. Other combinations between some non-polar, polar, uncharged and basic amino acids showed good activity. This is the case for alanine, valine, glycine, tyrosine and histidine, alanine, valine, glycine, glutamine and histidine and alanine, valine, leucine, glycine and histidine.

\section{DISCUSSION}

The involvement of amino acids from natural food extracts in feeding attraction or stimulation of fishes has been reported in a number of recent studies. In many species, amino acid fractions were found to be less potent stimuli than the crude extract. This is the case for the pinfish, Lagodon rhomboides (Carr \& Chaney, 1976), the pigfish, Orthopristis chrysopterus (Carr et al., 1977), the whiting, Merlangius merlangus and the cod, Gadus morhua (Pawson, 1977), the oriental weatherfish, Misgurnus anguillicaudatus (Harada \& Ikeda, 1984), the yellowtail, Seriola quinqueradiata (Harada \& Matsuda, 1984) and the Arctic charr, Salvelinus alpinus (Olsén et al., 1986).

In other fishes such as the Japanese eel, Anguilla japonica, and tilapia, Tilapia zillii, amino acids from food extracts have been shown to fully account for the activity of the crude extracts (Hashimoto et al., 1968; Takeda et al., 1984; Johnsen \& Adams, 1986). However, such categorizing has to be considered with caution since many factors can influence the amino acid composition of food organisms and the chemical sensitivity of fish to these compounds. First, the total and relative free amino acid contents of a food or prey organism do not only depend on the species examined but also on its history (place and time of capture, stage of development, nutritional state) (Johannes \& Webb, 1970; Dabrowski \& Rusiecki, 1983; Holm \& Walther, 1988). The method of collection of food organisms and the mode of preparation of crude extracts also have to be considered. Leakage of free amino acids can be different in undamaged, injured or dead zooplankton, and in Daphnia, Holm \& Walther (1988) have demonstrated a rapid leakage of free amino acids on thawing.

The behavioural responses of fish to amino acids can be influenced by stage of development and nutritional state, by the stocking conditions (rearing densities, physicochemical characteristics of water) and by the nature of the bioassay procedures and test apparatus (Johnstone, 1980; Shparkovskiy et al., 1983; Mearns, 1985; Mearns, 1989). Moreover, the nature of the food extract and the concentration tested can also have an influence on the relative contribution of free amino acids to the behavioural response of the fish (Carr et al., 1977; Olsen et al., 1986).

Tshushima and Ina (1978) found that a reconstituted free amino acid fraction for silkworm, Bombyx mori, pupa extract was less attractive than the crude extract for 
common carp. However, in the present study, juveniles of the same species were attracted to a mixture of the 17 free amino acids isolated from Tubifex extract to the same extent as they were to the crude extract.

These two studies show some differences in the nature of the 17 amino acids analysed and in the concentration tested. In addition, differences in the relative free amino acid composition of silkworm pupa and Tubifex extracts could partly account for this discrepancy. For instance, pupa extract shows much a higher content of acidic amino acids $(27 \cdot 1 \%)$ that Tubifex extract $(10.9 \%)$. Our observations have shown that acidic amino acids are not attractive when tested alone, and decrease attraction when they are tested in combination with an attractive mixture (alanine, valine and glycine). Such differences do not rule out the possible occurrence of other classes of attractive compounds in pupa of silkworm, as well as in Tubifex.

Our study shows that carp are highly sensitive to various combinations of amino acids, tested at the same proportion as in Tubifex extract. Among the 17 free amino acids isolated, we found that only a few of them were potent enough to produce significant attraction in an olfactometer. Attraction produced by some combinations of non-polar amino acids, polar, uncharged amino acids, or combinations between these two groups, was of similar importance as the attraction induced by the 17 amino acids or by the crude extract. In particular, we found that a simple combination of alanine, valine and glycine produced significant effects on both attraction and exploratory behaviour. At a dose corresponding to $500 \mathrm{mg} \mathrm{I}^{-1}$ of crude Tubifex extract, test concentrations for alanine, valine and glycine were $1.3 \times 10^{-7} \mathrm{moll}^{-1}, 3.7 \times 10^{-8} \mathrm{moll}^{-1}$ and $5 \times 10^{-8} \mathrm{moll}^{-1}$ respectively.

Electrophysiological recordings have shown that these amino acids are effective stimulants for the olfactory system of the carp (Goh \& Tamura, 1978). In addition, Marui et al. (1983) reported a high gustatory sensitivity of this species to alanine, with a threshold close to $10^{-8} \mathrm{~mol}^{-1}$.

In a previous study on juvenile carp tested in an olfactometer (Saglio \& Blanc, 1983), it has been shown that out of $21 \mathrm{~L}$-amino acids tested, alanine, valine and glycine were among seven amino acids (including arginine, histidine, tyrosine and cysteine) which induced attraction at only the lowest concentration tested $\left(1.3 \times 10^{-6} \mathrm{moll}^{-1}\right)$. Further experiments are needed to compare behavioural responses to glycine, valine and alanine when tested individually or in combinations and to determine the possible synergetic effects occurring between these three amino acids.

Glycine and alanine have been found to constitute active chemical components in the feeding behaviour of whiting and cod (Pawson, 1977), sole, Solea solea (Mackie et al., 1980), sea bream, Chrysophrys major (Ina \& Matsui, 1980; Murofushi \& Ina, 1981), plaice, Pleuronectes platessa (Mackie, 1982) and Japanese eel (Takeda et al., 1984).

Glycine and alanine are among the most abundant amino acids in the tissues and excretory products of aquatic invertebrates (Awapara, 1962; Kittredge et al., 1962; Webb \& Johannes, 1967; Dabrowski \& Rusiecki, 1983). Johnsen \& Adams (1986) suggested a possible relationship between the most stimulatory amino acids and those most abundant in the tissue of preferred food items for fish. However, amino acids present in relatively low amounts in crude extract can also be involved in the feeding response of the fish. This is the case for aspartic acid, isoleucine and 
phenylalanine in the pinfish, Lagodon rhomboides (from shrimp extract, Carr \& Chaney, 1976) and histidine in juvenile eel (from marine worm extract, Takeda et al., 1984). These two studies also indicate that amino acids which are present in high concentrations in the extracts do not appear to play any noticeable role in the feeding response. Our results with carp also indicate that there is no particular relationship between amino acids which constitute active combinations, and their relative abundance in Tubifex extract.

In the present work, free amino acids were isolated from a filtrate of frozen Tubifex. Owing to the high leakage of free amino acids which can occur on thawing (Holm \& Walther, 1988), further analyses are now required to determine which free amino acids are actually released by live Tubifex and to test the behavioural responses of carp to these amino acid emissions. These analyses appear necessary before stating that free amino acids are responsible for attraction of carp to live Tubifex in the natural environment.

More work is also needed to evaluate the relative importance of olfaction in the response of carp to the attractive free amino acid combinations identified here, and to check the eventual activity of these combinations on the stimulation of feeding.

We wish to thank Dr S. Kaushik for his helpful comments on the manuscript.

\section{References}

Adron, J. W. \& Mackie, A. M. (1978). Studies on the chemical nature of feeding stimulants for rainbow trout, Salmo gairdneri Richardson. Journal of Fish Biology 12, 303-310.

Atema, J., Holland, K. \& Ikehara, W. (1980). Olfactory responses of yellowfin tuna (Thunnus albacares) to prey odors: chemical search image. Journal of Chemical Ecology 6, 457-465.

Awapara, J. (1962). Free amino acids in invertebrates: a comparative study of their distribution and metabolism. In Amino Acid Pools (Holden, J. T., ed.), pp. 158-175. Amsterdam: Elsevier Scientific.

Caprio, J. (1982). High sensitivity and specificity of olfactory and gustatory receptors of catfish to amino acids. In Chemoreception in Fishes (Hara, T. J., ed.), pp. 109-134. Amsterdam: Elsevier Scientific.

Carr, W. E. S. \& Chaney, T. B. (1976). Chemical stimulation of feeding behavior in the pinfish, Lagodon rhomboides: characterization and identification of stimulatory substances extracted from shrimp. Comparative Biochemistry and Physiology 54A, 437-441.

Carr, W. E. S., Blumenthal, K. M. \& Netherton, J. C. III (1977). Chemoreception in the pigfish, Orthopristis chrysopterus: the contribution of amino acids and betaine to stimulation of feeding behavior by various extracts. Comparative Biochemistry and Physiology 58A, 69-73.

Dabrowski, K. \& Rusiecki, M. (1983). Content of total and free amino acids in zooplanktonic food of fish larvae. Aquaculture 30, 31-42.

Daumas, R. (1976). Variations of particulate proteins and dissolved amino acids in coastal sea water. Marine Chemistry 4, 225-242.

Fogg, G. E. (1966). The extracellular products of algae. Oceanography and Marine Biology: An Annual Review 4, 195-212.

Goh, Y.\& Tamura, T. (1978). The electrical responses of the olfactory tract to amino acids in carp. Bulletin of the Japanese Society of Scientific Fisheries 44, 341-344.

Hara, T. J. (1982). Structure-activity relationships of amino acids as olfactory stimuli. In Chemoreception in Fishes (Hara, T. J., ed.), pp. 135-157. Amsterdam: Elsevier Scientific. 
Harada, K. \& Ikeda, I. (1984). Feeding attractants in chemical constituents of lake Prawn for Oriental weatherfish. Bulletin of the Japanese Society of Scientific Fisheries 50, 617-622.

Harada, K. \& Matsuda, H. (1984). Feeding attractants in chemical constituents from the mid-gut gland of squid for juvenile yellowtail. Bulletin of the Japanese Society of Scientific Fisheries 50, 623-626.

Hashimoto, Y., Konosu, S., Fusetani, N. \& Nose, T. (1968). Attractants for eels in the extracts of short-necked clam. I. Survey of constituents eliciting feeding behavior by the omission test. Bulletin of the Japanese Society of Scientific Fisheries 34, 78-83.

Hellebust, J. A. (1974). Extracellular products. In Algal Physiology and Biochemistry (Stewart, W. D., ed.), pp. 838-863. Berkeley: University of California Press.

Hidaka, I. (1982). Taste receptor stimulation and feeding behavior in the puffer. In Chemoreception in Fishes (Hara, T. J., ed.), pp. 243-257. Amsterdam: Elsevier Scientific.

Hogan, D. L., Kraemer, K. L. D. \& Isenberg, J. I. (1982). The use of high-performance liquid chromatography for quantification plasma amino acids in man. Analytical Chemistry 127, 17-24.

Holm, J. C. \& Walther, B. T. (1988). Free amino acids in live freshwater zooplankton and dry feed: possible importance for first feeding in Atlantic salmon fry. Aquaculture 71, 223-234.

Ina, K. \& Matsui, H. (1980). Survey of feeding stimulants for the sea bream (Chrysophrys major) in the marine worm Perinereis vancaurica tetradentata. Journal of the Agricultural Chemical Society of Japan 54, 7-12.

Johannes, R. E. \& Webb, K. L. (1970). Release of dissolved organic compounds by marine and fresh water invertebrates. In Symposium on Organic Matter in Natural Waters (Hood, D. W., ed.), pp. 257-273. University of Alaska: Institute of Marine Science.

Johnsen, P. B. \& Adams, M. A. (1986). Chemical feeding stimulants for the herbivorous fish, Tilapia zillii. Comparative Biochemistry and Physiology 83A, 109-112.

Johnstone, A. D. F. (1980). The detection of dissolved amino acids by the Atlantic cod, Gadus morhua L. Journal of Fish Biology 17, 219-230.

Kawamura, T. \& Tamura, T. (1980). Responses of the pit organ to amino acids in carp. Bulletin of the Japanese Society of Scientific Fisheries 46, 1457-1463.

Kittredge, J. S., Simonsen, D. G., Roberts, E. \& Jelinek, B. (1962). Free amino acids of marine invertebrates. In Amino Acid Pools (Holden, J. T., ed.), pp. 176-186. Amsterdam: Elsevier Scientific.

Lindstedt, K. J. (1971). Chemical control of feeding behaviour. Comparative Biochemistry and Physiology 39A, 553-581.

Mackie, A. M. (1982). Identification of the gustatory feeding stimulants. In Chemoreception in Fishes (Hara, T. J., ed.), pp. 275-291. New York: Elsevier Scientific.

Mackie, A. M. \& Mitchell, A. I. (1983). Studies on the chemical nature of feeding stimulants for the juvenile European eel, Anguilla anguilla (L.). Journal of Fish Biology 22, $425-430$.

Mackie, A. M., Adron, J. W. \& Grant, P. T. (1980). Chemical nature of feeding stimulants for the juvenile Dover sole, Solea solea (L.). Journal of Fish Biology 16, 701-708.

Marui, T. \& Funakoshi, M. (1980). Comparison of chemoreceptions of terminal buds and pit organs of the carp, Cyprinus carpio L. Brain Research 193, 570-573.

Marui, T., Harada, S. \& Kasahara, Y. (1983). Gustatory specificity for amino acids in the facial taste system of the carp, Cyprinus carpio L. Journal of Comparative Physiology 153A, 299-308.

Mearns, K. J. (1985). Response of Atlantic salmon (Salmo salar L.) yearlings to individual L. amino acids. Aquaculture 48, 253-259.

Mearns, K. J. (1989). Behavioral responses of salmonid fry to low amino acid concentrations. Journal of Fish Biology 34, 223-232.

Murofushi, S. \& Ina, K. (1981). Survey of feeding stimulants for the sea bream present in the dried pupae of silkworms. Agricultural and Biological Chemistry 45, 1501-1 504. 
Nicol, J. A. C. (1967). The Biology of Marine Animals, 2nd ed. New York: Interscience.

Ogata, H., Murai, T. \& Nose, T. (1983). Free amino acid composition in urine of carp and channel fish. Bulletin of the Japanese Society of Scientific Fisheries 49, 1471.

Olsén, K. H. (1986). Modification of conspecific chemo-attraction in Arctic charr, Salvelinus alpinus (L.) by nitrogenous excretory products. Comparative Biochemistry and Physiology 85A, 1, 77-81.

Olsén, K. H., Karlsson, L. \& Helander, A. (1986). Food search behavior in Arctic charr, Salvelinus alpinus (L.) induced by food extracts and amino acids. Journal of Chemical Ecology 12, 1987-1998.

Pawson, M. G. (1977). Analysis of a natural chemical attractant for whiting Merlangius merlangus L. and cod Gadus morhua L. using a behavioural bioassay. Comparative Biochemistry and Physiology 56A, 129-135.

Saglio, Ph. \& Blanc, J. M. (1983). Etude en olfactomètre de la réponse comportementale aux L. acides aminés chez le juvéniles de Carpe, Cyprinus carpio L. Biology of Behaviour 8, 359-370.

Shparkovskiy, I. A., Pavlov, I. D. \& Chinarina, A. D. (1983). Behavior of young hatcheryreared Atlantic Salmo salar (Salmonidae), influenced by amino acids. Journal of Ichthyology 23, 140-148.

Sokal, R. R. \& Rohlf, F. J. (1969). Biometry. The Principles and Practice of Statistics in Biological Research. San Francisco: W. H. Freeman.

Takeda, M., Takii, K. \& Matsui, K. (1984). Identification of feeding stimulants for juvenile eel. Bulletin of the Japanese Society of Scientific Fisheries 59,645-651.

Tsushima, J. \& Ina, K. (1978). Survey of feeding stimulants for carps, Cyprinus carpio (studies on the feeding stimulants for fishes, part III). Journal of the Agricultural Chemical Society of Japan 52, 225-229.

Webb, K. L. \& Johannes, R. E. (1967). Studies of the release of dissolved free amino acids by marine zooplankton. Limnology and Oceanography 12, 376-382. 